Son cada vez más los artículos enviados a la Revista Colombiana de Ciencias Hortícolas - RCCH provenientes de varios países de América del Sur y El Caribe; para finales del mes de marzo se contaban 80 manuscritos en cola principalmente del vecino país, Brasil. El incremento de autores y lectores se debe a la reciente integración de la RCCH en nuevas bases de datos como Academic Search Ultimate (EBSCO) y Red Iberoamericana de Innovación y Conocimiento Científico (REDIB). Por ejemplo, en este número se consideraron 25 artículos en los idiomas: español, inglés y portugués, provenientes de Colombia, Brasil, Perú, Argentina y Venezuela.

En el Comité Editorial de la revista agradecemos la labor de varios años de los investigadores Alfredo Jarma (Universidad de Córdoba, Montería, Colombia) y Luz Marina Melgarejo (Universidad Nacional de Colombia - UNAL, Bogotá) y saludamos a los nuevos miembros de este comité Hernán Mauricio Romero (UNAL, Bogotá) y Christian Ulrichs (Universidad Humboldt de Berlín, Alemania), además la vinculación de Michael Blanke (Institute of Crop Science and Resource Conservation, Bonn, Alemania) al Comité Científico de la revista.

En el caso de la Sección de frutales, ocho artículos abordan los avances científicos en siete diferentes especies desde la tolerancia a la salinidad en Passiflora tarminiana, efecto del boro en gulupa (Passiflora edulis f. edulis) y la nutrición de N, P y K en tomate de árbol (Solanum betaceum). Además de los efectos del medio ambiente sobre los pedúnculos del marañón (Anacardium occidentale). Por otro lado, en el cultivo de piña se estudió la fluorescencia de la clorofila tras aplicación de herbicidas y en un segundo artículo se realiza la comparación de la fertilización mineral y biológica. La sección termina con el reporte por primera vez del daño por ácaros en fresa (Fragaria $\times$ ananassa) para Venezuela y el efecto del 1-MCP en higo (Ficus carica) sobre la calidad poscosecha.

Otros 10 artículos fueron considerados en la Sección de hortalizas, la más amplia del número con cuatro ensayos en tomate de mesa (Solanum lycopersicum). El primero investiga la nutrición de Ca y B en híbridos italianos. El segundo estudia la adición de compost sobre un sustrato de cascarilla de arroz en un sistema recirculante de lixiviados. El tercero mide el flujo de savia y potencial hídrico en tomates bajo invernadero, mientras el cuarto evalúa el rendimiento y fenología de tres genotipos de tomate cherry. En zapallo (Cucurbita moschata), se comprueba la habilidad combinatoria en función de la endogamia para la producción y peso del fruto. En pimiento (Capsicum aпnиит), en primer lugar, se estudia la eficacia de cuatro insecticidas botánicos en el control de pulgones, mientras en un segundo trabajo se investiga si el agua salobre es una opción para la producción de pimiento hidropónico en flujo laminar de nutrientes minerales. Para las crucíferas brócoli (Brassica oleracea L. var. italica) y coliflor (Brassica oleracea L. var. botrytis), se proyecta un perfil de riesgo en la aplicación de plaguicidas organofosforados durante su cadena productiva. Por último en esta sección, se estudia la elaboración de un alimento para ganado bovino a base de zanahoria (Daucus carota) mediante fermentación en estado sólido.

Un grupo de artículos en aumento son los correspondientes a la Sección de plantas aromáticas y medicinales, donde el primero de ellos informa la aplicación de abonos verdes en el rendimiento del perejil (Petroselinum crispum) y la fertilidad del suelo, 
mientras un segundo trabajo estudia el efecto del $\mathrm{N}$ y K sobre el intercambio gaseoso y la distribución de biomasa en albahaca (Ocimum basillicum). Un estudio subsiguiente en estevia (Stevia rebaudiana), trata los efectos del ácido indolbutírico sobre las posiciones de estacas y sustratos de propagación vegetativa. En la crasulácea Kalanchoe daigremontiana, se aborda el efecto de la colchicina sobre la morfología foliar y los estomas.

Por una parte, la Sección de otras especies presenta el desempeño fisiológico de nueve genotipos de cacao bajo dos especies forestales en Santander (Colombia), mientras que en la Sección de cambio climático se investigó la influencia del clima sobre el contenido de carbono orgánico del suelo en dos pisos altitudinales andinos del departamento Norte de Santander, con respecto al uso del suelo y su profundidad.

Este fascículo termina con un artículo de revisión sobre los aspectos fisiológicos y de aprovechamiento de Acacia mangium.

La Revista Colombiana de Ciencias Hortícolas está realizando nuevos cambios para dar respuesta a la demanda de artículos que se encuentran sometidos. Gracias al apoyo y respaldo de sus tres instituciones editoras, Sociedad Colombiana de Ciencias Hortícolas, Universidad Pedagógica y Tecnológica de Colombia y la Universidad Francisco de Paula Santander en los aportes financieros, fortalecimiento de los recursos humanos y nuevos recursos tecnológicos. Por otro lado, la revista cambia su frecuencia de publicación a tres veces al año y seguirá buscando ingresar a nuevas bases e índices bibliográficos.

\section{Gerhard Fischer}

Editor en Jefe 